\title{
Electron Microscopy of the Mouse Cerebral Cortex in Unstained, Fresh Air-dried Spreads and Fresh Frozen Dried Ultrathin Sections
}

\author{
By \\ KENICHI TAKAYA \\ Department of Anatomy, Faculty of Medicine, Toyama Medical and \\ Pharmaceutical University, 2630 Sugitani, Toyama, Japan \\ -Received for Publication, December 1, 1981-
}

Key words: Fresh air-dried spreads, Fresh frozen dried ultrathin sections, Mouse brain, Synaptic bouton, Unstained.

\begin{abstract}
Summary: Fresh air-dried spreads and fresh frozen ultrathin sections dried with nitrogen gas flow were evacuated at less than $10^{-8}$ torr for more than $10 \mathrm{hr}$. They were observed by conventional electron microscopy at an accelelation voltage of 40-100 kV. Synaptic boutons filled with synaptic vesicles, ribosomes, vesicular structures, mitochondria containing fine dense granules and thin myelin, were recognized in the fresh spreads of the cerebral cortex. The cell nucleus, cytoplasm, dendrites, myelin and synaptic boutons with mitochondria attached to a cell process were seen in fresh frozen dried sections but no synaptic vesicles were identified. These specimens prepared without any chemical treatment or evaporation are expected to be applicable to various kinds of microbeam analysis.
\end{abstract}

Electron probe microanalysis has been applied extensively to biological specimens, especially to electron microscopic sections $(22,23)$. Energy and wave dispersive type spectrometers have been employed for $\mathrm{X}$-ray microanalysis of biological specimens in combination with electron microscopes for image formation, including transmission electron microscopes, scanning transmission electron microscopes and scanning electron microscopes with a scanning transmission attachment. Recently, the applicability of energy loss analyzers to biological section has been extensively examined (4, 9, 19, 20). For the detection of organic compounds, photoemission microscopes are available $(10,12)$. Ion microprobe mass analyzers or ion microscopes $(5,11,26,30)$ and laser microprobe mass analyzers $(16,21,31)$ can be utilized to reveal organic compounds and elements of electrolytes and metals in biological specimens.

Many investigators have attempted to preserve diffusible substances in situ in cells and tissues as nearly as possible where they are in the living state. Fresh frozen dried ultrathin sections are one of the most ideal for the purpose, but many difficulties still exist in obtaining sections without ice crystal artifacts $(1,8,24,25$, 27). Electron microscopy of unstained, fresh air-dried spreads of various animal soft tissues has disclosed well-preserved 
fine structures, and X-ray microanalysis of the spreads has shown that the elements are well preserved (28).

Electron microscopy of fresh air-dried spreads of the mouse cerebral cortex has revealed neurons with a nucleolus, synaptic regions containing synaptic boutons, and thin myelin with a central lucent band corresponding to the axon. Individual synaptic vesicles were discernible in some boutons. Energy dispersive X-ray microanalysis of the spreads indicated a high content of magnesium in the neuron nucleus and synaptic boutons (28).

The present paper describes an improved technique for demonstrating the fine structures of the mouse cerebral cortex in fresh air-dried spreads by drying the spreads further in vacuo, and a method for preparing fresh frozen dried thin sections of the mouse cerebral cortex, although the latter is still preliminary.

\section{Materials and Methods}

Fresh Air-dried Spreads, Further Dried under High Vacuum

Fresh air-dried spreads of mouse cerebral cortex on a collodion membrane over copper grids (180 mesh) (28) were dried in vacuo at less than $10^{-8}$ torr for $10 \mathrm{hr}$ to 7 days in a freeze specimen processing device, FD-2A (Eiko Engineering, Ltd.), using a liquid nitrogen trap. The specimens were observed without further treatment under an electron microscope (JEM-100S) at an acceleration voltage of $40-100 \mathrm{kV}$.

\section{Fresh Frozen Dried Ultrathin Sections}

Small pieces of fresh cerebral cortex were dissected with a razor blade and attached to the tip of a copper chuk. They were quenched by lightly contacting the specimens on the polished surface of a copper block (8), or by immersing them in Freon13, (Daifron-13, Daikin Kogyo Co., Ltd.) precooled with liquid nitrogen (24). They were then transferred to a cryokit chamber (Sorval) attached to an ultramicrotome MT-IIb (Sorval). Sections were cut at $-90^{\circ} \mathrm{C}$ with a section thickness of 100 $120 \mathrm{~nm}$. The cut sections were placed on collodion film-covered copper grids (180 mesh) and pressed with the polished tip of a copper rod (Sorval). The grids were put in a glass chamber (27) within the cryokit. The specimens were dried by continuous nitrogen gas flow from a liquid nitrogen dewar by means of a creek pump at the cutting temperature $\left(-90^{\circ} \mathrm{C}\right)$ for $2-5 \mathrm{hr}$, and the temperature of the cryokit chamber was then gradually elevated up to room temperature during $2-4 \mathrm{hr}$. The grids were transferred to an FD-2A for further drying in vacuo at less than $10^{-8}$ torr for 2-4 days at room temperature. The dried sections were observed without any other treatment under an electron microscope (JEM-100S) at an acceleration voltage of $40-100 \mathrm{kV}$.

\section{Results}

Fresh air-dried spreads, further dried under high vacuum

Electron microscopy of unstained, fresh air-dried and vacuum-dried spreads of mouse cerebral cortex confirmed the previous findings for the fine structures observed in air-dried spreads of the mouse cerebral cortex. Neurons with a large nucleus and a prominent nucleolus were seen. Smaller cells of unknown types were also encountered. The most conspicuous were the fine structures in synaptic regions. A previous report (28) has revealed scattered synaptic boutons which contained worm-like, homogeneous dense structures corresponding to mitochondria. Synaptic vesicles could be seen in some of the boutons. Close observations of the air-dried and vacuum-dried spreads revealed distinct features of synaptic boutons containing synaptic 
vesicles (Fig. 1, arrows). The synaptic boutons appeared round or ovoid and about $1 \mu \mathrm{m}$ in diameter. They were enclosed by a continuous membrane which showed no specialization corresponding to presynaptic membrane thickening as seen in conventional electron microscopic sections. They included homogeneous dense wormlike structures containing a large number of fine dense particles (Fig. 1, mt). They probably corresponded to mitochondria. Some of them showed crista structures, although they were not visible in the boutons shown in Fig. 1. Most vesicles were round or elliptical. Some boutons contained elongated vesicles (Fig. 1, arrow E). There were dispersed accumulations of fine dense particles with irregular contours, about $20 \mathrm{~nm}$ in diameter. Since they revealed an arrangement of rough endoplasmic reticulum in several places, most of them were ribosomes. Cyst-like structures with thin walls filled the interspaces among the boutons (Fig. 1, C), but they could not be correlated with the fine structures of the cerebral cortex disclosed in conventional ultrathin sections. There were small round vacuoles with clear edges probably due to artifacts (a), whose precise nature was unclear. Thin myelin around an axon was seen to consist of two parallel, dense lines sandwiching the lucent axon between them (Fig. 2, my), traversing over the cytoplasm of the cell. In the cytoplasm of the cell, accumulations of ribosomes ( $r$ ) were free or in close contact with membranous structures appearing as elongated or oval vacuoles (v) linked together by small tubes. At high magnification, they exhibited an oval shape and their size was approximately $190 \times 280 \mathrm{~nm}$.

\footnotetext{
Fresh frozen dried ultrathin sections, frozen dried under high vacuum

In contrast to the fresh air-dried and evacuated spreads of the cerebral cortex in which the fine structures could be
}

easily and reproducibly demonstrated, the preservation of structures in the fresh frozen dried ultrathin sections was generally poor. The chance of obtaining good sections in which no ice crystal artifacts had developed was small. Moreover, the fine structures including synaptic vesicles and individual ribosomes were barely recognizable in fresh frozen dried ultrathin sections.

Electron microscopy of fresh frozen dried ultrathin sections of the mouse cerebral cortex frozen by the metal contact method failed to produce good sections for revealing the fine structures. The cells were filled with filamentous structures and no organelles could be discerned in the cy toplasm, although a large clear neuron nucleus with a prominent nucleolus and the surrounding cytoplasm were frequently disclosed.

Electron microscopy of sections obtained by quenching the specimens in Freon 13 precooled with liquid nitrogen revealed cells and their processes, synaptic regions, and cross sections of myelin. Fig. 3 shows part of the nucleus of a cell with sparse heterochromatin. The cytoplasm of the cell was full of fine dense dots, some of which showed an arrangement of rough endoplasmic reticulum ( $r$ ), although the exact nature of the cell was dubious. In the right corner of Fig. 3, a cell process containing abundant ribosome-like dense particles, which was probably a dendrite (D), can be seen. The boundaries of the cell cytoplasm and the cell process are indicated by solid arrows. Many boutonlike structures were attached to the cell process and situated between the process and the cell cytoplasm. Two of them are surrounded by open arrows. The straight thick membranes on the surface of the cell processes, three of which are shown by the lines between two arrows, probably corresponded to the attachment membranes of the synaptic boutons to the cell pro- 
cesses. They contained one or two slender, homogeneously dense worm-like structures, and a few of them had fine dense particles, probably representing mitochondria. No synaptic vesicles were clearly identified, although there were some small dots of intermediate density dispersed within the synaptic bouton.

There are several distinct artifacts in the sections shown in Fig. 3. The dense stripes (d) were probably due to displacement of part of the sections during cryocutting, and corresponded to 'ripples' (3). Breaks in the sections were caused by ice-crystal artifacts $(\mathrm{Br})$. The area around number 3 in Fig. 3 was due to wrinkling of the edge of the section. A string of vesicles at the perinuclear cistern of the cell was induced by electron beam damage.

\section{Discussion}

Morgan et al. (22) and Morgan (23) have reviewed preparatory techniques for biological materials for X-ray microanalysis. They discussed whole mounting and airdrying in more detail and concluded that such a procedure was inadequate for the preservation of local intracellular compartments of electrolytes in addition to ionic absorption, while air-drying was useful for detecting the chemical constituents of whole cells and certain discrete, highly mineralized intracellular structures.

Two groups of investigators were cited who were of opposite opinion regarding the usefulness of the air-drying procedure for the localization of intracellular electrolyte elements by X-ray microanalysis. Gullasch and Kaufmann (13) and Werner and Gullasch (32) compared the results of air-dried and fresh frozen hydrated, frozen erythrocytes, Tetrahymena pyriformis and rat spermatozoa. They indicated that analysis of the air-dried specimens could not disclose peaks of X-ray counts of electrolyte elements comparable to those obtained in that of cryofixed specimens on a frozen stage. On the other hand, Chandler and Battersby (6) performed quantitative studies on electrolytes retained in several regions of human spermatozoa after different preparatory procedures, and concluded that subcellular compartments of the electrolytes could be disclosed as in the case of fresh frozen dried, frozen sections. Chandler and Battersby (7) also confirmed their results using the sperm head with five different preparatory techniques including air-drying, freeze dried frozen sections, freeze substitution, pyroantimonate treatment and conventional electron microscopic sections.

Successful preparation of fresh frozen dried ultrathin sections has been reported by Christensen (8) and Appleton (1). Electron microscopy of the sections revealed that the integrity of the cell was well preserved and identification of the fine structures was possible. There were, however, abundant minute holes in the cell, especially in the cytoplasm, probably corresponding to ice crystal artifacts which presumably developed during quenching of the specimen, cryocutting or freezedrying (8). Hodson and Marshall $(17,18)$ attempted to cut fresh frozen dried ultrathin sections and analyzed the mechanism of cryosection cutting. Takaya (27) reported a technique for preparinge fresh frozen dried ultrathin sections by drying the sections with a continuous flow of dry nitrogen gas. The sections were relatively free of artifacts, and fine structures such as mitochondrial cristae and nuclear substructures were visible.

Fresh frozen dried ultrathin sections have been employed extensively for the localization of ions in cells by quantitative X-ray microanalysis. Appleton (2) examined the epithelium of the snail, and Somlyo and his group examined cryosections in order to study the electrolyte 
elements in different kinds of muscle fibers by quantitative X-ray microanalysis (24, 25). Fresh frozen hydrated sections were applied in the quantitative localization of electrolyte elements in epithelial cells (14, 15). In preliminary studies using fresh air-dried spreads and fresh frozen dried ultrathin sections of mouse cerebral cortex which were further dehydrated under high vacuum, electrolyte elements were shown to be well preserved by energy dispersive $\mathrm{X}$-ray microanalysis (29). They are probably applicable in other types of microbeam analysis as cited above.

Christensen (8) emphasized the usefullness of a dry nitrogen gas flow for the freeze drying of ultrathin sections. He suggested that sections of less than 100 $\mathrm{nm}$ in thickness could be amply dried out in an hour, although it was difficult to determine the exact length of time required for complete drying. He freeze dried the sections on grids by the flow of dry nitrogen gas from a liquid nitrogen dewar employed for cooling the cryostat chamber which he himself devised. A special glass apparatus was employed for the freeze drying of sections by continuous flow of dry nitrogen gas with a Reichert ultramicrotome and its cryokit (27). This ultramicrotome and cryokit were utilized to examine the effect of a difference in temperature between the knife and specimen during the cutting of fresh frozen sections. No distinct advantage was revealed according to the temperature difference between knife and specimen for the preparation of cryo-sections of fresh biological materials (27). The same glass apparatus was employed for the freeze drying of sections with the ultramicrotome MT-IIb with a cryokit (29). Dry nitrogen gas was introduced into the glass apparatus by means of a creek pump from another liquid nitrogen dewar apart from that used for cooling the cryokit chamber. The procedure permitted a constant flow of dry nitrogen gas around the specimens. It is, however, necessary to measure and determine the most effective speed of flow and that of rise in temperature, which are to be regulated automatically. A trial is at present in progress in our laboratory.

Fine structures of the cerebral cortex were clearly manifested in air-dried and evacuated spreads of cerebral cortex. The mechanism of increase of contrast in the electron microscopic images of the airdried and evacuated spreads was probably related to further dehydration of the specimen.

\section{References}

1) Appleton, T.C.: 'Dry' ultrathin frozen sections for electron microscopy and Xray microanalysis; the cryostat approach. Micron, 3: 101-105, 1972.

2). Appleton, T.C.: The contribution of cryo-ultramicrotomy to X-ray microanalysis in biology. ed. by Erasmus, D. A. Electron Probe Microanalysis in Biology. pp. 148-182 Chapman and Hall, London 1978.

3) Barnard, T. and Seveus, L.: Preparation of biological material for X-ray microanalysis of diffusible elements. II. Comparison of different methods of drying ultrathin cryosections cut without at rough liquid. J. Microsc., 112 : 289-291, 1978.

4) Bazett Jones, D. P. and Ottensmeyer, F.P.: Phosphorus distribution in the nucleosome. Science, 211: 169-170, 1981.

5) Bellhorn, M. B. and Lewis, R. K. : Localization of ions in retina by secondary ion mass spectrometry. Exp. Eye Res., 22: 505-518, 1976.

6) Chandler, J.A. and Battersby, S.: X-ray microanalysis of ultrathin frozen and freeze-dried sections of human sperm cells. J. Microsc., 107: 55-65, 1976.

7) Chandler, J. A. and Battersby, S.: X-ray microanalysis of diffusible and nondiffusible elements in ultrathin biological tissues using human sperm cells as a model for investigating specimen preparation. ed. by Lechene, C.P. and Warner, R.R. 
Microbeam Analysis in Biology. pp. 457477 Academic, New York, 1979.

8) Christensen, A.K.: Frozen thin sections of fresh tissue for electron microscopy, with a description of pancreas and liver. J. Cell Biol., 51 : 772-804, 1971.

9) Costa, J.L., Joy, D.C., Maher, D. M., Kirk, K.L. and Hui, S.W.: Fluorinated molecule as a tracer: Difluoroserotonin in human platelets mapped by electron energy-loss spectroscopy. Science, $200: 537$ 539, 1978.

10) Dam, R., Nadakavukaren, K. K. and Griffith, O.H.: Photoelectron microscopy of cell surfaces. J. Microsc., 111: 211-217, 1977.

11) Galle, P. and Lefevre, R.: Secondary ion emission microanalysis: biomedical applications. ed. by Lechene, C.P. and Warner, R.R. Microbeam Analysis in Biology, pp. 117-127 Academic Press, New York, 1979.

12) Grund, S., Eichberg, J. and Engel, W.: Biologische Strukturen im Photoelektronenemissionsmikroskop. Semidunnschnitte von Kukenleber in den Einbettungsmitteln Durcupan, Vestopal, Araldit und Epon. J. Ultrastr. Res., 64 : 191-203, 1978.

13) Gullasch, J. and Kaufmann, R.: Energydispersive $\mathrm{X}$-ray microanalysis in soft biological tissues: Relevance and reproducibility of the results as deponding on specimen preparation (air-drying, cryofixation, cool-stage techniques). ed. by Hall, T., Echlin, P. and Kaufmann, R. Microprobe Analysis as Applied to Cells and Tissues, pp. 175-190, Academic, London and New York, 1974.

14) Gupta, B. L., Hall, T. A., Maddrell, S. H.P. and Moreton, R.B.: Distribution of ions in a fluid transporting epithelium determined by electron-probe X-ray microanalysis. Nature, $264:$ 284-287, 1976.

15) Gupta, B.L., Naftalin, R. J. and Hall, T.A.: Microprobe measurements of concentrations and gradients of $\mathrm{Na}, \mathrm{K}$, and $\mathrm{Cl}$ in epithelial cells and intercellular spaces of rabbit ileum. Nature, 272:7073, 1978.

16) Hillenkamp, F., Kaufmann, R., Nitsche, R., Remy, E. and Unsold, E.: Recent re- sults in the development of a laser microprobe. ed. by Hall, T., Echlin, P. and Kaufmann, R. Microprobe Analysis as Applied to Cells and Tissues, pp. 1-14, Academic, London and New York, 1974.

17) Hodson, S. and Marchall, J.: Ultramicrotomy a technique for cutting ultrathin frozen sections of unfixed biological tissues. for electron microscopy. J. Microsc., 91 : 105-117, 1970.

18) Hodson, S. and Marshall, J.: Evidence against through-section thawing whilst cutting on the ultracryotome. J. Microsc., 95: 459-466, 1972.

19) Johnson, D. E. : Energy loss spectrometry for biological research. ed. by Hren, J. J., Goldstein, J.I. and Joy, D.C. Introduction to Analytical Electron Microscopy, pp. 245-258, Plenum Press, New York and London, 1979.

20) Joy, D.C. and Maher, D. M.: A practical electron energy loss spectrometer. ed. by Lechene, C.P. and Warner, R. R. Microbeam Analysis in Biology, pp. 87-97, Academic Press, New York, 1979.

21) Kaufmann, R., Hillenkamp, A., Nitsche, R., Schumann, M. and Unsold, E.: Medical application of laser microprobe analysis. J. Microsc. Biol. Cell., 22: 389-398, 1975.

22) Morgan, A. J. : Preparation of specimens. Changes in chemical integrity. ed. by Hayat, M. A.: X-ray Microanalysis in Biology, pp. 65-165, University Park Press, Baltimore, 1980.

23) Morgan, A. J., Davis, T.W. and Erasmus, D. A. : Specimen preparation. ed. by Erasmus, D.A. Electron Probe Microanalysis in Biology, pp. 94-147, Chapman and Hall, London, 1978.

24) Somlyo, A. V., Schuman, H. and Somlyo, A.P.: Elemental distribution in striated muscle and the effects of hypertonicity. Electron probe analysis of cryosections. J. Cell Biol., 71: 828-857, 1977.

25) Somlyo, S. P., Sloane, B. F., Somlyo, A. V., H. and Scarpa, A.: Mitochondrial calcium content in vascular smooth muscle. ed. by Lechene, C.P. and Warner, R.R. pp. 557-567, Academic Press, New York, 1979. 
26) Stika, K.M., Bielat, K. L. and Morrison, G. H.: Diffusible ion localization by ion microscopy: a comparison of chemically prepared and fast-frozen, freeze-dried, unfixed liver sections. J. Microsc., 118 : 409-420, 1980.

27) Takaya, K.: Preparation of fresh frozen dried ultrathin sections without vacuum. Acta Anat., 96 : 248-258, 1976.

28) Takaya, K.: Electron microscopy of unstained, fresh air-dried spreads of the mouse brain and application to energy dispersive X-ray microanalysis. Arch. Histol. Jap., 42 : 533-542, 1979.

29) Takaya, K., Miyata, K. and Hoshino, T. : Magnesium distribution in the mouse brain studied by energy and wave dis- persive X-ray microanalysis using fresh air-dried spreads and fresh frozen-dried ultrathin sections. (Abstract) J. Electr. Microsc., $27:$ 339-340, 1978.

30) Truchet, M.: Application histologique de la microanalyse par emission ionique secondaire. J. Microsc. Biol. Cell, 22: 465-474, 1975.

31) Wechsung, R., Hillenkamp, F., Kaufmann, R., Nitsche, R. and Vogt, H. : Laser-Mikrosonden-Massen-Analysator "LAMMA": Ein neues Analysen-verfahren fur Forschung und Technologie. Mikroskopie, 34 : 47-54, 1978.

32) Werner, G. and Gullasch, J.: Rontgenmikroanalyse an Rattespermien. Microskopie, 30 : 95-101, 1974. 


\section{Explanation of Figures}

\section{Plate I}

Fig. 1. A fresh air-dried spread of mouse cerebral cortex evacuated for $48 \mathrm{hr}$ at less than $10^{-8}$ torr, as observed by conventional electron microscopy at an acceleration voltage of $40 \mathrm{kV}$. Arrows indicate synaptic boutons containing synaptic vesicles. mt, Mitochondria; arrow E, synaptic bouton with elongated vesicles; $\mathrm{C}$, cyst-like structures; a, artifacts in the specimen. The bar indicates $1 \mu \mathrm{m} . \quad \times 19,400$.

Fig. 2. A spread of mouse cerebral cortex prepared and observed as in Fig. 1. There are accumulations of ribosomes ( $r$ ), dispersed freely or attached to the membranous structures as vesicles $(\mathrm{v})$. Thin myelin containing a thin axon (my) traversed the cell cytoplasm. The bar indicates $1 \mu \mathrm{m} . \quad \times 20,000$. 

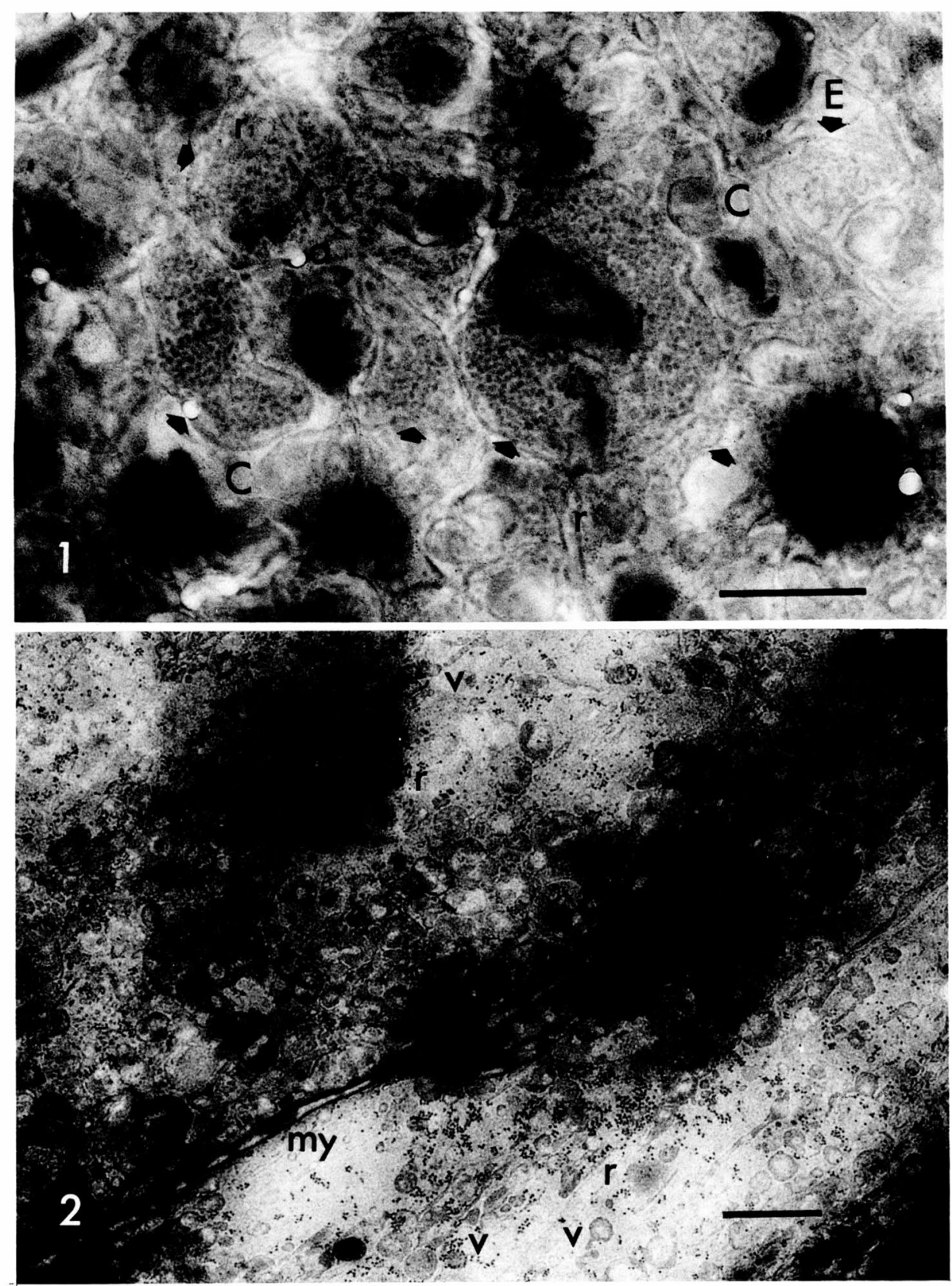

K. Takaya 


\section{Plate II}

Fig. 3. Fresh frozen dried ultrathin section, dehydrated further under vacuum and observed by conventional electron microscopy at an acceleration voltage of $40 \mathrm{kV}$. A cell with cytoplasm and a nucleus, a cell process and neuropil between them, are visible. A string of vesicles at the perinuclear cistern of the cell was induced by electron beam bombardment of the specimen. r, Ribosomes; D, dendrite; d, dense stripes; $n$, nucleus; Cy, cytoplasm of the cell ; $\mathrm{Br}$, break in the section. $\boldsymbol{\tau}$ indicates the edge of the cytoplasm. $\nearrow$ shows the areas of contact of synaptic boutons onto the dendrite membrane. The regions surrounded by $\hat{\imath}$ correspond to synaptic boutons (S). The bar indicates $1 \mu \mathrm{m} . \quad \times 20,800$. 
Plate II

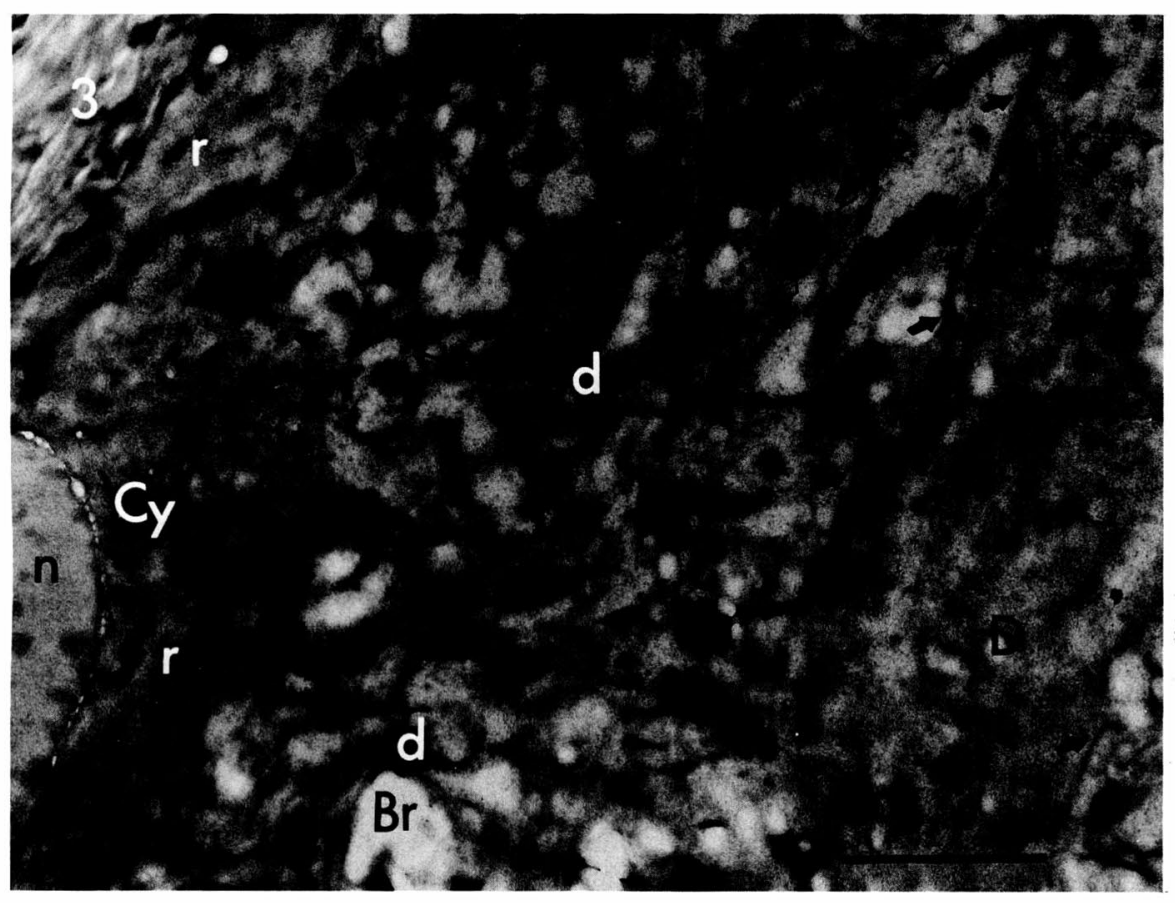

K. Takaya 